\title{
Life-Style and Substance Use Among Male African-American Urban Adolescents: A Cluster Analytic Approach ${ }^{1}$
}

\author{
Marc A. Zimmerman ${ }^{2}$ \\ University of Michigan \\ Kenneth I. Maton \\ University of Maryland Baltimore County
}

Cluster analyzed four variables: school attendance, employment, church attendance, and delinquency, to develop life-style profiles. Data from 218 African-American urban adolescents were used in the study. Five meaningful clusters were retained and subjected to criterion validity analyses using measures of spirituality, participation in a voluntary organization, self-esteem, and friend's substance use. The five clusters were then compared on cigarette, alcohol, marijuana, and hard drug use. The results suggest that a life-style that includes an adaptive compensatory behavior component may be more adaptive than a life-style that does not include compensatory behavior. For example, youths who left high school before graduation but were involved in church reported less alcohol and substance use than youths who left school and were not involved in any meaningful instrumental activity. Implications for intervention and future research on high-risk behaviors are discussed.

\footnotetext{
${ }^{1}$ This research was supported by the National Institute on Drug Abuse, Grant No. RO1DA04766, and the U.S. Department of Justice, Office of Juvenile Justice and Delinquency Prevention, Grant No. 87JNCX0010. The authors thank Doug Luke, Deborah A. Salem, Linda M. Chatters, and Valire Carr Copeland for their thoughtful comments on earlier drafts of this paper. We also express our thanks to the research staff of the Baltimore Youth Study and the youths who participated in the study.

${ }^{2}$ All correspondence should be sent to Marc A. Zimmerman, Department of Health Behavior and Health Education, School of Public Health, University of Michigan, Ann Arbor, Michigan 48109-2029.
} 
This research examines the relationship of life-style patterns and alcohol and substance use among African-American male adolescents. Life-style refers to the collective actions that characterize an individual's typical behavioral pattern (e.g., one's characteristic work, family, school, and leisure time activities). This may include daily behaviors such as going to school or commuting to work; weekly actions such as weekend alcohol use or church attendance; or less regular but consequential behaviors such as illicit acts. The research literature suggests that alcohol and substance use are related to behaviors that several investigators have referred to as life-styles (Bachman, Johnston, O'Malley, \& Humphrey, 1988; Brunswick \& Messeri, 1986; Dembo, Schmeidler, \& Burgos, 1980; Newcomb, McCarthy, \& Bentler, 1989). Most of this research, however, has focused on single behaviors (e.g., delinquency, school attendance, church involvement) and has not examined several different behaviors simultaneously. A multivariate approach may be more appropriate because it can represent the complexity of a behavioral pattern that may more accurately represent a life-style.

A life-style approach does not necessarily suggest that individuals alone are responsible for their life-style. Contextual factors may be a salient feature of the activities in which one engages. The availability of resources, opportunities to engage in different activities, and the relevance of institutional programs (e.g., school programs) may hinder or facilitate life-style choices and actions. One goal of this research is to explore the notion that a life-style that includes potentially detrimental behaviors may not be harmful if the negative behaviors are compensated for by other more instrumental activities.

Involvement in "meaningful instrumental activities" (Maton, 1990, p. 298) may have a positive effect on adolescent health and well-being. Maton defined meaningful instrumental activities as task- or skill-related experiences that have positive implications for one's psychological well-being and sense of environmental mastery. Instrumental activities may help to overcome the apparent negative effects of other life-style behaviors. For example, leaving high school before graduation may be related to drug use among some adolescents; however, others who leave school, but who are involved in a potentially beneficial activity such as church participation, may show different patterns of alcohol and substance use. Instrumental activity (e.g., school attendance, church involvement) has been associated with selfesteem (Maton, 1990) and life satisfaction (Feather \& O'Brien, 1986; Maton, 1990) in samples of adolescents. Research also suggests that meaningful participation may be related to an increased sense of psychological empowerment (Berger \& Neuhaus, 1977; Kieffer, 1984; Zimmerman \& Rappaport, 1988) and learned hopefulness (Zimmerman, 1990). 
A number of investigators have explored life-style predictors of adolescent alcohol and substance use (Bachman et al., 1988; Dembo et al., 1980; Farrow \& French, 1986; Hartnagel \& Krahn, 1989; Hawkins \& Weiss, 1984; Jessor, Chase, \& Donovan, 1980; Newcomb et al., 1989). The lifestyle variables that are consistently examined in this literature include deviant behavior (Dembo et al., 1980; Hartnagel \& Krahn, 1989; Jessor et al., 1980), school attendance (Bachman, O'Malley, \& Johnston, 1980; Bachman et al., 1988; Friedman, Glickman, \& Utada, 1985; Johnston, 1973; Kandel, 1975), employment status (Hartnagel \& Krahn, 1989; Steinberg, Greenberger, Garduque, Ruggiero, \& Vaux, 1982), and religious involvement (Bachman et al., 1988; Donovan \& Jessor, 1978; Selnow, 1985).

Research examining the relationship between life-style and substance use among African-American adolescents is lacking. Crawford, Washington, and Senay (1980) examined the relationship between substance use and life-style among African-American adults. They found heavy users and addicts were more involved in deviant life-styles such as criminal behavior. These results are somewhat limited as their sample consisted of adults only, grouped respondents based on their heroin use, and examined only one life-style behavior. Brunswick and Messeri (1986) studied life-style longitudinally among a sample of urban African-American youths. Their life-style variables included formal participation, obtaining public assistance, and a summative index of being incarcerated, idleness, and dropping out of high school. They examined life-style effects on health, however, and did not specifically study substance use.

In summary, the research literature suggests that adolescent life-style behaviors are associated with alcohol and substance use. School attendance and church involvement have been found to be negatively associated with alcohol and substance use. Delinquent behaviors are associated with more alcohol and substance use among adolescents. Work status has been found to be related to marijuana use but not to alcohol consumption. These studies, however, have examined life-style variables in isolation. Univariate approaches may not fully capture the complex nature of life-style patterns. An alternative, more integrative approach is to examine several behaviors simultaneously which together constitute an individual's overall life-style. In addition, previous studies have typically explored life-style variables among predominantly white samples. Multivariate approaches and research on African-American youth are lacking (Benson \& Donohue, 1989; Prendergast, Austin, Maton, \& Baker, 1989; Singleton, 1989).

A primary goal of this research is to investigate a compensatory hypothesis that suggests some life-style behaviors (e.g., church involvement) may offset the effects of other potentially harmful life-style behaviors (e.g., school dropout). A multivariate approach, cluster analysis, was used to form 
life-style profiles that combine school attendance, work status, church attendance, and delinquent behavior. These four behaviors were studied because they represent behaviors consistently reported in the research literature as risk factors associated with adolescent alcohol and substance use.

A cluster analytic approach was used because we were interested in identifying how behaviors that have traditionally been studied separately may be grouped together to form multivariate behavioral profiles. This approach may be more ecologically valid than other more traditional approaches (e.g., regression analysis) because it simultaneously combines several behaviors to uncover meaningful, integrative behavioral patterns that may more accurately be termed a life-style. In addition, cluster analysis forms groups that both maximize within group homogeneity (intraclass similarity) and between group heterogeneity (interclass differences). This allows for a test of a compensatory hypothesis by comparing alcohol and substance use across different life-style profiles that may be similar on some dimensions (behaviors) but dissimilar on others (i.e., by including vs. not including a compensatory life-style behavior).

\section{METHOD}

\section{Research Participants}

The sample consisted of 218 African-American male adolescents from inner-city Baltimore. Their mean age was 17 years $(S D=1.49)$. Seventy percent $(n=153)$ left school before graduation. Most of the youths left school in the 9th $(n=45 ; 29 \%)$ and 10th $(n=41 ; 27 \%)$ grades $(M=$ 9.4; $S D=1.19$ ). At the time of the interview youths no longer attending school had been out of school for an average of 10.7 months $(S D=9.98)$.

One-hundred thirty-two youths reported their fathers were employed and 30 reported their fathers were unemployed (62 youths did not answer this question); 167 reported their mothers were employed (51 were unemployed). Only six cases were missing for mother's employment status. The average highest year completed in school for fathers was $12.3(S D=1.7)$ with only $16 \%$ of reported cases $(n=113 ; 52 \%)$ having less than a 12 thgrade education. The mean for mother's highest grade completed was 12.4 $(S D=2.0)$ with $24 \%$ having less than a 12th-grade education $(n=177$; $81 \%)$. Ninety-three youths (44\%) said they spent no time with their fathers, and only $50(23 \%)$ spent more than 10 hours per week with their father. 


\section{Procedure}

Youths were recruited to participate in the study in four ways: (a) mail solicitations of randomly selected youths from school district dropout lists ( $n=72 ; 33 \%$ ); (b) recruitment by peers paid to enlist youths from their neighborhoods $(n=35 ; 16 \%)$; (c) referrals from community programs such as the Urban League $(n=80 ; 37 \%)$; and (d) solicitation through media, posters, and flyers $(n=29 ; 13 \%)$. Two cases had missing data.

Participants were informed that all information shared with the research team was confidential and was legally protected from subpoena. They were paid $\$ 15$ for an initial 90 -minute interview. Structured interviews and questionnaires were verbally administered by trained interviewers. These measures were followed with a series of open-ended questions. Consent forms from both the youths and their parents (if they were under 18 year of age) were obtained. Nine trained interviewers, both African-American $(n=4)$ and white $(n=5)$, male $(n=2)$ and female $(n=7)$, performed the interviews.

\section{Quality of the Data}

The truthfulness of the youths' responses is a concern because the interview included questions about unlawful behavior (i.e., illicit substance use). We used three strategies to help address this problem. The first strategy was to build their trust by guaranteeing confidentiality. We assured the youth that we would not use the data for any purpose other than research. We also obtained subpoena protection (i.e., Federal Confidentiality Certificate) from one of our granting agencies to assure the youths that the information they shared with us could not be obtained by the police or the courts. We presented the certificate to them at the beginning of the interview.

Second, we trained interviewers to work on building rapport with the youths. Interviewers conducted several supervised practice interviews with male African-American adolescents from the community. Feedback was sought from these youths about response accuracy and interview content and relevance. The youths noted that the interview seemed like it would be relevant and acceptable to their peers, and emphasized that developing rapport was the best strategy for ensuring truthful responses.

Finally, interviewers rated each interview they conducted on several dimensions using a 3-point scale (good, bad, neutral). They rated the youths' consistency of response, comprehension of the questions, flow or ease of the interview, and the youths' attention. The interviewers rated their 
overall impression of the youths' attitudes about the interview and also rated their impression of the validity of responses for each measure in the interview using a 3-point scale (valid, questionable, not valid). Any respondent with more than four invalid or questionable ratings was dropped from the study. Four youths were eliminated using this procedure. Despite these efforts to improve the accuracy of the youths' reports of alcohol and substance use behavior, it is still possible that the youths did not accurately report their substance use.

\section{Data Analytic Procedure}

Three primary data analytic procedures were used in this study. The first step was to cluster the youths with respect to four life-style behaviors that have received much attention in the research literature on adolescent alcohol and substance use-school attendance, delinquency, church attendance, and employment. Two randomly divided subsamples (approximately a $60 / 40 \%$ split) were used to establish a cross-validation (i.e., reliability) of the cluster solution. The sample as a whole was then clustered for the purpose of defining groups for subsequent analyses. Ward's method, which uses squared euclidean distances as a proximity measure, was the clustering technique used. This method was selected because we had no a priori grounds for narrowing down the number of clusters which iterative procedures (e.g., k-means procedure) usually require.

Two procedures recommended by Aldenderfer and Blashfield (1984) were used to determine the number of clusters to retain. These were (a) graphing the number of clusters by the proximity coefficients and inspecting the jump in values of the proximity coefficients; and (b) examining the theoretical meaningfulness of different solutions (see also Everitt, 1974).

The second analytic step examined the validity of the clusters. Several criterion measures were compared across the groups defined by the cluster solution using a one-way analysis of variance. The final step examined group differences on alcohol and substance use. Several subanalyses were also conducted to examine recruitment effects, interviewer effects, demographic differences, and social desirability.

\section{Measures}

Cluster Variables. Four life-style variables: school attendance, employment status, church attendance, delinquency, were used in the cluster analysis. School attendance and employment status were dichotomous variables indicating whether or not the youth was in school or left before graduation, 
and whether or not he was working. Youths who worked 13 hours or more per week were considered to be working (only two employed youths worked less than 10). A 13-hour per week cutoff was used because it roughly matched the 15 hours worked per week reported by Steinberg, Greenberger, Garduque, Ruggiero, \& Vaux (1982) as potentially detrimental for youths. Only 1 youth worked 13 hours; all others who were employed worked 15 hours or more per week. Church attendance was measured by a single 5-point Likert item asking the youth how often he attended church (Maton, 1989). Delinquency was measured by summing four dichotomous items asking the youth if he had ever been in trouble with the police, been arrested, appeared before a juvenile court, or been incarcerated. Delinquency scores could range from no delinquency (4) to very delinquent (8). The internal reliability (Cronbach alpha) of the 4-item delinquency measure for this sample was .79 .

Criterion Validity Variables. Four criterion validity measures: organizational involvement, spirituality, self-esteem, and friend's drug use, were used to test the meaningfulness of the clusters. Organizational involvement was measured by a single 5-point Likert item. Youths were asked to indicate how often during the past week they contributed to the goals of a group or organization ( 5 was coded as very often). Three 5-point Likert items were used to measure spirituality (Maton, 1989). Cronbach's alpha for this sample was .80 . A representative item read: "I experience a close personal relationship with God." Rosenberg's (1965) self-esteem scale was also used. This is a 10-item scale with a Cronbach alpha of .75 for this sample. A representative item read: "I feel that I'm a person of worth, at least on an equal basis with others." The youths were also asked about a friend's alcohol and substance use over the past 6 months. This measure, adapted from Newcomb and Harlow (1986), used a 6-point Likert scale to indicate the frequency of use over the past 6 months $(6$ was coded as more than once a day, 1 was coded as not at all). They rated how often their friends used each of the following substances during the past 6 months: liquor (beer, wine and, hard liquor); marijuana; cocaine and its derivatives; pills (barbiturates and amphetamines); hallucinogens; phencyclidine (PCP); and heroin. A composite measure of friend's drug use was developed that summed frequencies across all substances.

Alcohol and Substance Use. The youths were asked to rate their frequency of use over the past 6 months for each of the following substances: cigarettes, alcohol, marijuana, and hard drugs. The same procedures were used as when rating their friend's drug use. A composite alcohol use variable was developed by summing each youth's frequency ratings for beer, wine, and hard liquor. Similarly, hard drug use was a composite of the 
ratings for cocaine and its derivatives, heroin, hallucinogens, pills, and PCP. Marijuana and cigarette use were each measured by one item.

Socioeconomic Status. Socioeconomic status (SES) was measured by the number of years of school completed by the youths' parents. If data from both parents were available the one with the highest educational level was used; otherwise information on whichever parent the youth reported was used. The coding for this variable ranged from less than junior high school (1) to at least some education beyond college (7).

Social Desirability. The social desirability scale from Jackson's Personality Research Form (Jackson, 1967) was used to measure response bias.

\section{RESULTS}

\section{Cluster Analysis}

A five-cluster solution was chosen to represent the data because the graph of the proximity measures began to flatten at the fourth and fifth clusters, the jump in proximity coefficients was the largest between four and five clusters, and a five-cluster solution separated groups that were conceptually consistent with previous research. Means of the cluster-analyzed variables for the two subsamples are reported in Table I. The solutions for each subsample indicate similar profiles. For example, the most delinquent group was also the group lowest on church attendance in both subsamples. A five-cluster solution was used for the analysis of the total group.

Means for the four clustered variables and group size for the total sample five-cluster solution are reported in Table II. The first cluster is the largest group $(n=62)$ and the fifth cluster is the smallest group ( $n=$ $26)$. The solution replicates the split-sample analyses. The first cluster includes the most delinquent youths and those least involved in school, work, or church. The second cluster is distinguished by the highest church attendance. The third cluster is notable by its low score on all four variables (i.e., not delinquent but also not involved in school, work, or church). The fourth cluster includes the school attenders and Cluster 5 is the only group that includes employed youths.

Similar cluster assignments were made for $93 \%(n=202)$ of the respondents in both the split-half and total sample analyses. The most discrepancies were found between Groups 4 and $2(n=9)$. In the final analysis, Cluster 2 included some youths who were in school, however, this group included mostly youths who left school as evidenced by the mean and standard deviation of school attendance for this group (1.3 and 0.45 , 
Table I. Descriptive Statistics for the Subsample (46\%; 54\%) Cluster Solutions ${ }^{a}$

\begin{tabular}{|c|c|c|c|c|c|}
\hline \multirow[b]{2}{*}{ Variable } & \multicolumn{5}{|c|}{ Cluster $^{b}$} \\
\hline & 1 & 2 & 3 & 4 & 5 \\
\hline \multicolumn{6}{|c|}{ School attendance } \\
\hline$M$ & 1.0 & 1.0 & 1.0 & 2.0 & 1.7 \\
\hline$S D$ & 0 & 0 & 0 & 0 & 0.47 \\
\hline \multicolumn{6}{|l|}{$54 \%$} \\
\hline$M$ & 1.0 & 1.0 & 1.0 & 2.0 & 1.5 \\
\hline$S D$ & 0 & 0 & 0 & $\mathbf{0}$ & 0.52 \\
\hline \multicolumn{6}{|l|}{$\begin{array}{l}\text { Employment } \\
46 \%\end{array}$} \\
\hline$M$ & 1.0 & 1.0 & 1.0 & 1.0 & 2.0 \\
\hline$S D$ & 0 & 0 & 0 & 0 & 0 \\
\hline \multicolumn{6}{|l|}{$54 \%$} \\
\hline$M$ & 1.0 & 1.0 & 1.0 & 1.0 & 2.0 \\
\hline$S D$ & 0 & 0 & 0 & 0 & $\mathbf{0}$ \\
\hline \multicolumn{6}{|c|}{ Church attendance } \\
\hline \multicolumn{6}{|l|}{$46 \%$} \\
\hline$M$ & 1.2 & 4.3 & 1.4 & 2.6 & 2.2 \\
\hline$S D$ & 0.41 & 0.82 & 0.49 & 1.2 & 1.4 \\
\hline \multicolumn{6}{|l|}{$54 \%$} \\
\hline$M$ & 1.5 & 4.8 & 1.7 & 2.3 & 2.1 \\
\hline$S D$ & 0.76 & 0.45 & 0.93 & 1.5 & 1.1 \\
\hline \multicolumn{6}{|l|}{ Delinquency } \\
\hline \multicolumn{6}{|l|}{$46 \%$} \\
\hline$M$ & 7.4 & 5.1 & 4.7 & 4.6 & 4.9 \\
\hline$S D$ & 0.49 & 1.4 & 0.87 & 1.1 & 1.4 \\
\hline $54 \%$ & & & & & \\
\hline$M$ & 7.5 & 5.8 & 5.1 & 5.0 & 5.3 \\
\hline$S D$ & 0.51 & 1.3 & 0.80 & 1.2 & 1.4 \\
\hline
\end{tabular}

${ }^{a} \mathrm{~A}$ score of 2 indicates in-school or working and a score of 1 indicates left school before graduation or not employed. Higher scores for church attendance and delinquency indicate more frequent attendance and more delinquency.

${ }^{b}$ Cluster $1=$ delinquent group; 2 = church group; 3 = uninvolved group; 4 = in-school group; 5 = employed group.

respectively). The church attendance variable probably accounted for the discrepant group assignments in the two subsamples.

\section{Cluster Validation}

Means, standard deviations, and paired comparisons across the five clusters for the criterion validity measures are reported in Table III. No differences were found across groups for self-esteem, $F(4,212)=0.30$, ns, 
Table II. Descriptive Statistics for the Full Sample Cluster Solution ${ }^{a}$

\begin{tabular}{lccccc}
\hline & \multicolumn{5}{c}{ Cluster $^{b}$} \\
\cline { 2 - 6 } \multicolumn{1}{c}{ Variable } & $\begin{array}{c}1 \\
(n=62)\end{array}$ & $\begin{array}{c}2 \\
(n=38)\end{array}$ & $\begin{array}{c}3 \\
(n=52)\end{array}$ & $\begin{array}{c}4 \\
(n=40)\end{array}$ & $\left.\begin{array}{c}5 \\
=26\end{array}\right)$ \\
\hline $\begin{array}{l}\text { School attendance } \\
M\end{array}$ & 1.0 & 1.3 & 1.0 & 2.0 & 1.6 \\
$S D$ & 0 & 0.45 & 0 & 0 & 0.50 \\
Employment & & & & & \\
$M$ & 1.0 & 1.0 & 1.0 & 1.0 & 2.0 \\
$S D$ & 0 & 0 & 0 & 0 & 0 \\
Church attendance & & & & & \\
$M$ & 1.4 & 4.4 & 1.3 & 1.9 & 2.1 \\
$S D$ & 0.66 & 0.75 & 0.47 & 0.81 & 1.2 \\
Delinquency & & & & & \\
$M$ & 7.4 & 4.9 & 4.9 & 5.0 & 5.2 \\
$S D$ & 0.50 & 1.2 & 0.87 & 1.3 & 1.4 \\
\hline
\end{tabular}

${ }^{a} \mathrm{~A}$ score of 2 indicates in-school or working and a score of 1 indicates left school before graduation or not employed. Higher scores for church attendance and delinquency indicate more frequent attendance and more delinquency.

${ }^{b}$ Cluster $1=$ delinquent group; 2 = church group; $3=$ uninvolved group; $4=$ in-school group; 5 = employed group.

Table III. Means, Standard Deviations, and Paired Comparisons of Criterion Validity Measures Across Cluster Groups

\begin{tabular}{|c|c|c|c|c|c|c|}
\hline \multirow[b]{2}{*}{ Variable } & \multicolumn{5}{|c|}{ Cluster $^{a}$} & \multirow{2}{*}{$\begin{array}{c}\text { Paired } \\
\text { comparisons }^{b}\end{array}$} \\
\hline & 1 & 2 & 3 & 4 & 5 & \\
\hline \multicolumn{7}{|c|}{ Group contribution } \\
\hline$M$ & 2.4 & 2.9 & 2.6 & 3.4 & 3.3 & \multirow{2}{*}{$\begin{array}{c}5,4>1,3 \\
{[F(4,212)=4.16]^{c}}\end{array}$} \\
\hline$S D$ & 1.4 & 1.4 & 1.4 & 1.2 & 1.4 & \\
\hline \multicolumn{7}{|c|}{ Friend's substance use } \\
\hline$M$ & 1.8 & 1.6 & 1.7 & 1.6 & 1.8 & \multirow{2}{*}{$\begin{array}{c}1>2,4 \\
{[F(4,212)=2.55]^{d}}\end{array}$} \\
\hline$S D$ & 0.39 & 0.50 & 0.45 & 0.50 & 0.40 & \\
\hline \multicolumn{7}{|l|}{ Self-esteem } \\
\hline$M$ & 41.5 & 42.3 & 41.5 & 42.6 & 41.8 & \multirow{2}{*}{$\begin{array}{c}F \text { test ns } \\
{[F(4,212)=0.30]}\end{array}$} \\
\hline$S D$ & 6.5 & 5.5 & 5.3 & 5.8 & 5.9 & \\
\hline \multicolumn{7}{|l|}{ Spirituality } \\
\hline$M$ & 9.0 & 11.7 & 9.2 & 11.0 & 9.7 & \multirow{2}{*}{$\begin{aligned} 2,4 & >1,3 \\
2 & >5 \\
{[F(4,212)} & =5.09]^{c}\end{aligned}$} \\
\hline$S D$ & 4.1 & 2.6 & 3.5 & 2.9 & 3.4 & \\
\hline
\end{tabular}

${ }^{a}$ Cluster $1=$ delinquent group; $2=$ church group; $3=$ uninvolved group; $4=$ in-school group; 5 = employed group.

${ }^{b}$ Duncan's multiple range procedure was used to examine group differences.

$c p<.01$.

$d_{p}<.05$. 
but spirituality did differ across groups, $F(4,212)=5.09, p<.01$. The group reporting the most church attendance also reported the most spirituality. The clusters also differed on group contribution, $F(4,212)=4.16$, $p<.01$. The youths most involved in school or work reported the most contribution to a voluntary organization. The church attendance group did not differ from any other group on this variable. Youths in different clusters also reported different drug use among their friends, $F(4,212)=2.55, p$ $<.05$. Friends' substance use was highest among the most delinquent group, but it was only significantly higher than Clusters 2 (church attenders) and 4 (school attenders).

\section{Alcohol and Substance Use}

The last analysis examined group differences for alcohol and substance use. The percentage of youths reporting no use of substances during the past 6 months was $58 \%$ for cigarettes $(M=2.1 ; S D=2.7), 36 \%$ for alcohol $(M=2.1 ; S D=2.5), 59 \%$ for marijuana $(M=1.1 ; S D=1.7)$, and $86 \%$ for hard drugs $(M=0.64 ; S D=2.6)$. Table IV reports the correlations among the alcohol and substance use variables. The correlations are all significant.

Table $\mathrm{V}$ reports the means, standard deviations, and paired comparisons for the alcohol and substance use measures across the five clusters. The clusters differed on all substances but in different ways. The first cluster (the delinquent group) consistently reported more use of all substances; however, Cluster 3 (low involvement group) also reported more use of cigarettes and alcohol than the school group (Cluster 4). Similarly, both Cluster 3 (low involvement group) and Cluster 5 (employed group) reported more marijuana use than either the church- (Cluster 2) or school- (Cluster 4) attending youths. Hard drug use was highest for the delinquent group (Cluster 1).

Table IV. Correlations Among Alcohol and Substance Use Measures $^{a}$

\begin{tabular}{lcccc}
\hline \multicolumn{1}{c}{ Variable } & 1 & 2 & 3 & 4 \\
\hline 1. Cigarettes & - & & & \\
2. Alcohol & .40 & - & & \\
3. Marijuana & .47 & .50 & - & \\
4. Hard drugs & .25 & .36 & .48 & - \\
\hline
\end{tabular}

${ }^{a}$ All correlations are significant at the .01 level. 
Table V. Means, Standard Deviations, $F$ Tests, and Paired Comparisons of Substance Use Measures Across the Cluster Groups

\begin{tabular}{lcccccc}
\hline & \multicolumn{5}{c}{ Cluster $^{a}$} & $\begin{array}{c}\text { Paired } \\
\text { Variable }\end{array}$ \\
\cline { 2 - 6 } comparisons $^{b}$
\end{tabular}

${ }^{a}$ Cluster 1 = delinquent group; $2=$ church group; $3=$ uninvolved group; $4=$ in-school group; $5=$ employed group.

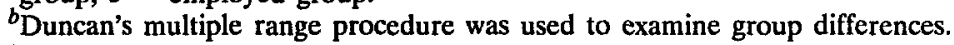
${ }^{c} p<.01$.

A secondary analysis identical to that described in Table $V$ was performed, except that it eliminated those youth in the church participation group (Cluster 2) that were in school $(n=10)$. The main effects of cluster membership for all the dependent variables remained significant, but Duncan paired comparison tests indicated some differences from the total sample analysis. Cluster 2 remained second lowest for alcohol and marijuana use. Cluster 2 was not significantly different from the other groups for alcohol use, but remained significantly lower than the delinquent group (Cluster 1) for both marijuana and hard drug use. The paired comparisons for cigarette use were the only analyses that actually changed in the secondary analysis. In this secondary analysis, Cluster 2 changed from second lowest in cigarette use to second highest and was higher than the in-school group (Cluster 4).

\section{Demographic and Other Effects}

Socioeconomic status, $F(4,181)=1.65$, ns, and social desirability, $F(4,211)=0.94$, ns, did not differ across the five clusters. Age did differ across clusters, $F(4,211)=5.11, p<.01$. The employed group (Cluster 5) 
comprised the oldest youths, whereas the school attenders (Cluster 4) were the youngest. When age was entered as a covariate in an analysis of cluster differences for alcohol and substance use all main effects remained significant.

Alcohol and substance use were compared across the four recruitment strategies used in the study. Only cigarette use differed by recruitment strategy, $F(3,214)=6.13, p<.01$. Youths recruited through random mailings reported the most cigarette use. When a two-way analysis of variance was computed for recruitment strategy by cluster membership $(4 \times 5$ ANOVA) with cigarette use as the dependent variable, the interaction effect was not significant and the main effect for cluster membership remained significant.

The analysis of interviewer effects for both gender and race of the interviewer on reported alcohol and substance use revealed mixed results. No differences for alcohol or substance use was reported by youths interviewed by male versus female interviewers. Only marijuana use differed for interviewer race, $F(1,218)=4.88, p<.05$. Youths with African-American interviewers reported more marijuana use than those with white interviewers. No interaction effects were found when interviewer race was included in a two-way ANOVA, and the main effect for cluster membership remained significant beyond the .01 level.

\section{DISCUSSION}

The results suggest that some life-style behaviors may have a compensatory effect on other potentially harmful life-style behaviors. We found that the five life-style profiles, defined by youths' school and church attendance, work status, and delinquency, were differentially associated with alcohol and substance use among urban male African-American adolescents. Four of the five profiles included youths who left school before graduation, yet differences in the quantity of alcohol and substance used were found across the five groups. These results suggest that there may be significant heterogeneity within a single ethnic group and among youths who left school.

The five life-style profiles can be described as (a) delinquent youths; (b) church attenders; (c) uninvolved youths; (d) school attenders; and (e) employed youths. The uninvolved youths left school, were not working, did not attend church, and were not delinquent. They differ from the delinquent youths only in that they did not report being in trouble with the police. The church attenders left school before graduation, were not delinquent, and did not work. School attenders did not work, attend church, or get into trouble with the police. The employed group comprised some youths who were in school and some who left school, but whose common 
characteristic was some type of employment. These youths did not attend church regularly nor were they delinquent. The results suggest that multivariate behavioral profiles may more accurately reflect the complexity of youths' life-styles than single behaviors measures.

Previous research identified high school dropout as a risk factor for alcohol and substance use, however, our data suggest that leaving school before graduation is not necessarily related to alcohol and substance use. Leaving school before graduation may not lead to alcohol and substance use if other life-style behaviors are also present (e.g., church involvement). Although we did replicate previous findings that school attendance (Bachman et al., 1980; Friedman et al., 1988; Johnston, 1973) and church involvement (Bachman et al., 1988; Donovan \& Jessor, 1978; Selnow, 1985) are related to less alcohol and substance use, some youths in our sample who left school before graduation but who did not attend church also reported low use. The results suggest that beneficial behaviors may compensate for other more detrimental behaviors and that future research to further examine this compensatory hypothesis is warranted.

An alternative explanation of the results might be that it is simply a combination of high school dropout and delinquency that is predictive of alcohol and substance use. Indeed, the uninvolved youth reported less alcohol and substance use than a group of youths with similar life-styles on every dimension except delinquency. Further research that examines different potentially offsetting life-style behaviors may be necessary. For example, the uninvolved youth may have been involved in activities that would be expected to compensate for leaving school before graduation (e.g., Boys Club, vocational skills training) but were not measured. The life-style profiles developed were based solely on behavioral variables so future research could also include beliefs and attitudes (e.g., deviant attitudes, religious convictions, future orientation).

A potential threat to the validity of the compensatory hypothesis is the fact that the church participation group (Cluster 2) included some inschool youths. A secondary analysis that eliminated school attenders from Cluster 2 provided a more stringent test of the compensatory hypothesis. This analysis indicated only slight differences from the total sample analysis for alcohol, marijuana, and hard drug use, but cigarette use did change in the secondary analysis. Cluster 2 changed from second lowest to second highest on cigarette use. This result may be partly due to the fact that church participation may inoculate youths from alcohol and drug use because of moral concerns, but does not address the less morally questionable behavior of cigarette use. Overall, the secondary analysis results provide additional validation that future research on the compensatory hypothesis is justified. 
Perhaps the most interesting pattern of alcohol and substance use was for the employed group. They reported the highest levels of alcohol consumption, and their marijuana use was similar to the uninvolved group. As $60 \%$ of the youths in this group remained in school, this result suggests that staying in school may not be a panacea for adolescent alcohol and substance use. Specifically, working while attending school may limit the potential benefits provided by school. Work may expose youths to older co-workers who consume alcohol and influence their behaviors, the demands of both work and school may increase stress that results in alcohol use as a coping mechanism, or working may simply provide a material means for purchasing alcohol. Future research that examines the relationship between school attendance, work status, and alcohol and substance use may help identify circumstances under which youth employment is beneficial or detrimental to youths.

The negative effect of working while attending school is similar to that found by Steinberg et al. (1982) who reported that youths who were working while attending high school indicated high levels of cigarette and marijuana use. Their sample differs from the one reported in this research in several ways: (a) they were predominantly white; (b) over half of the sample included females; and (c) all of the respondents were in school. These differences may explain why we found high levels of alcohol consumption as opposed to cigarette use in the working group. For instance, one reason for our dissimilar results might be related to gender differences. Smoking prevalence among adolescents is greater among women than men (U.S. Dept. of Health \& Human Services, 1980). Another reason for the disparate results might be related to the school status of the youths. Youths who leave school before graduation have reported more alcohol use than their in-school counterparts (Friedman et al., 1988).

Our confidence in the results are enhanced by the relatively minor influence of several external factors. Age did not eliminate the main effects of alcohol and substance use on cluster membership, even though the employed group comprised older adolescents. Interviewer race and sex were also not significant factors in explaining the association between cluster membership and alcohol and substance use. The nonrandom nature of the sample may raise some concerns about the generalizability of the results, but selection effects did not appear to influence the results. The only selection effects found were for random mailings which located more cigarette smokers than other recruitment strategies, but this did not interact with or reduce the main effect of life-style. Nevertheless, future research should use a random sampling strategy.

A limitation of the research was the use of a single method of measurement (i.e., self-report), though an interview method was selected to 
help develop rapport and generate accurate information. The limits of the self-report data are somewhat attenuated by the fact that social desirability did not differ across groups. We also employed several strategies to help improve the quality of the data reported in the study. Finally, we only measured frequency of alcohol and substance use, but did not measure intensity of use (i.e., amount consumed or used per occasion). Intensity of use may be a crucial element for understanding the detrimental effects of alcohol and substance use. For example, life-styles that include experimental use may be related to positive adolescent adjustment (Shedler \& Block, 1990), however, adolescents whose life-styles invite infrequent but large amounts of use may be at high risk for subsequent psychological and behavioral problems. Another limitation of this and previous research is that the crosssectional nature of the data does not address the issue of causal direction. Future research should examine the relationship between school attendance and substance use longitudinally.

While specific combinations of life-style behaviors may be predictive of substance use, this should not be interpreted as providing evidence that characteristics inherent in urban male African-American adolescents indicate eventual substance use. The life-style variables used in this research are very much related to behaviors connected to community institutions. For example, leaving school before graduation may be related to the characteristics of the urban school and not an inherent trait of the youths. Similarly, the accessibility of churches that target youth involvement may be a critical factor for church participation rather than specific attributes of the youths. Neighborhood characteristics and social ecology may also be substantial factors in determining a youth's life-style. Future research should begin to examine environmental factors that may facilitate or inhibit different life-style behaviors.

Fine (1983) suggested that school dropouts are not necessarily the socially deviant, unintelligent, and aggressive individuals as they are often stereotyped. Our results support this view as evidenced by the fact that youths who were not in school had diverse life-styles outside of school. The fact that youths may leave school before graduation for different reasons may explain why we found different alcohol and substance use among students who left school early. Another area for future research might be to examine whether different reasons for leaving school have differential effects on subsequent alcohol and substance use or other health behaviors.

The results of this research suggest that life-styles that engage urban African-American youths in alternative meaningful instrumental organizations and activities may help prevent adolescent alcohol and substance use. This approach suggests that the development of new programs or enhancement of existing settings to be more relevant and challenging to youths 
may be a worthwhile intervention strategy for preventing alcohol and substance use. Gibbs (1984) suggested several prevention efforts that focus on institutional change that may help to increase the life-style choices available for youths. Efforts that focus on improving schools, church programs, or voluntary organizations may help to enhance healthy life-styles and reduce alcohol and substance use without blaming adolescents for their problems.

This research provides initial support for a multivariate life-style approach for understanding adolescent alcohol and substance use. A benefit of this approach is its emphasis on a repertoire of behaviors that interact in ways that may compensate for potentially deleterious behaviors, rather than focus on separate high-risk behaviors. A compensatory perspective emphasizes a positive approach to adolescents and encourages efforts to find what is right in their lives, rather than what is wrong. This perspective may be especially informative for understanding minority youth because they are often assumed to possess many of the high-risk factors related to drug use. This research may help challenge stereotypes as they refer to young African-American males and dispute the notion that dropping out of high school is necessarily associated with alcohol and substance use as either a cause or consequence.

\section{REFERENCES}

Aldenderfer, M. S., and Blashfield, R. K. (1984). Cluster analysis. Beverly Hills: Sage.

Bachman, J. G., O'Malley, P. M., \& Johnston, L. D. (1980). Correlates of drug use, Part I: Selected measures of background, recent experiences, and life-style orientations. Monitoring the Future (Occasional Paper 8). Ann Arbor, MI: Institute for Social Research.

Bachman, J. G., Johnston, L. D., O'Malley, P. M., \& Humphrey, R. H. (1988). Explaining the recent decline in marijuana use: Differentiating the effects of perceived risks, disapproval, and general lifestyle factors. Journal of Health and Social Behavior, 29, 92-112.

Benson, P. L., \& Donahue, M. J. (1989). Ten-year trends in at-risk behaviors: A national study of Black adolescents. Journal of Adolescent Research, 4, 125-139.

Berger, P. J., \& Neuhaus, R. J. (1977). To empower people: The Role of mediating structures in public policy. Washington, DC: American Enterprise Institute for Public Policy Research.

Brunswick, A. F., \& Messeri, P. (1986). Drugs, lifestyle, and health: A longitudinal study of urban Black youth. American Journal of Public Health, 76, 52-57.

Crawford, G. A., Washington, M. C., \& Senay, E. C. (1980). Early life-style differences among Black male heroin addicts and their nonaddicted friends. American Joumal of Drug and Alcohol Abuse, 7, 193-210.

Dembo, R., Schmeidler, J., \& Burgos, W. (1980). Life-style and drug involvement among youths in an inner city junior high school. International Journal of the Addictions, 15, 171-188.

Donovan, J. E., \& Jessor, R. (1978). Adolescent problem drinking: Psychosocial correlates in a national sample. Journal of Studies in Alcohol, 39, 1506-1524.

Everitt, B. (1974). Cluster analysis. London: Heinemann.

Farrow, J. A., \& French, J. (1986). The drug abuse-delinquency connection revisited. Adolescence, 21, 951-960. 
Feather, N. T., \& O'Brien, G. E. (1986). A longitudinal study of the effects of employment and unemployment on school leavers. Journal of Occupational Psychology, 59, 121-144.

Fine, M. (1983). Perspectives on inequity: Voices from urban schools. In L. Bickman (Ed.), Applied psychology annual $I V$, Beverly Hills, CA: Sage.

Friedman, A. S., Glickman, N., \& Utada, A. (1985). Does drug and alcohol use lead to failure to graduate from high school? Journal of Drug Education, 15, 353-364.

Gibbs, J. T. (1984). Black adolescents and youth: An endangered species. American Journal of Orthopsychiatry, 54, 6-21.

Hartnagel, T. F., \& Krahn, H. (1989). High school dropouts, labor market success, and criminal behavior. Youth and Society, 20, 416-443.

Hawkins, J., \& Weiss, J. G. (1984). The social development model: An integrated approach to delinquency prevention. Journal of Primary Prevention, 5, 21-36.

Jackson, D. N. (1967). Personality Research Form manual. Goshen, NY: Research Psychologists Press.

Jessor, R., Chase, J. A., \& Donovan, J. E. (1980). Psychosocial correlates of marijuana use and problem drinking in a national sample of adolescents. American Journal of Public Health, 70, 604-613.

Johnston, L. D. (1973). Drugs and American youth. Ann Arbor, MI: Institute for Social Research.

Kandel, D. (1975). Reaching the hard to reach: Illicit drug use among high school absentees. Addictive Diseases, 1, 465-480.

Kieffer, C. H. (1984). Citizen empowerment: A developmental perspective. Prevention in Human Services, 3, 9-36.

Maton, K. I. (1989). The stress buffering role of spiritual support: Cross-sectional and prospective investigations. Journal for the Scientific Study of Religion, 28, 310-323.

Maton, K. I. (1990). Meaningful involvement in instrumental activity and well-being: Studies of older adolescents and at risk urban teen-agers. American Joumal of Community Psychology, 18, 297-320.

Newcomb, M. D., \& Harlow, L. L. (1986). Life events and substance use among adolescents: Mediating effects of perceived loss of control and meaningfulness in life. Journal of Personality and Social Psychology, 51, 564-577.

Newcomb, M. D., McCarthy, W. J., \& Bentler, P. M. (1989). Cigarette smoking, academic lifestyle, and social impact efficacy: An eight-year study from early adolescence to young adulthood. Journal of Applied Social Psychology, 19, 251-281.

Prendergast, M. L., Austin, G. A., Maton, K. I., \& Baker, R. (1989, Spring). Substance use among black youth (Prevention Research Update 3). Los Alamitos, CA: Western Center for Drug-Free Schools and Communities.

Rosenberg, M. (1965). Society and the adolescent self-image. Princeton, NJ: Princeton University Press.

Selnow, G. W. (1985). Using a stratified approach in substance intervention and prevention programs among adolescents: An empirical analysis. Journal of Drug Education, 15, 327-341.

Shedler, J., \& Block, J. (1990). Adolescent drug use and psychological health: A longitudinal inquiry. American Psychologist, 45, 612-630.

Singleton, E. G. (1989). Substance use and black youth: Implications of cultural and ethnic differences in adolescent alcohol, cigarette, and illicit drug use. In R. L. Jones (Ed.), Black adolescents (pp. 385-401). Berkeley, CA: Cobb \& Henry.

Steinberg, L. D., Greenberger, E., Garduque, L., Ruggiero, M., \& Vaux, A. (1982). Effects of working on adolescent development. Developmental Psychology, 18, 385-395.

U.S. Department of Health and Human Services. (1980). The health consequences of smoking for women, a report of the surgeon general. Rockville, MD: Office of Smoking and Health.

Zimmerman, M. A. (1990). Toward a theory of learned hopefulness: A structural model analysis of participation and empowerment. Journal of Research in Personality, 24, 71-86.

Zimmerman, M. A., \& Rappaport, J. (1988). Citizen participation, perceived control, and psychological empowerment. American Journal of Community Psychology, 16, 725-750. 